\title{
An Assessment of High-Power Thyristor Technology
}

R. I. Scace

Electron Devices Division

Center for Electronics and Electrical Engineering

National Engineering Laboratory

National Bureau of Standards

Washington, D.C. 20234

October 1978

Final

Prepared for

Jepartment of Energy

Jivision of Electric Energy Systems

$Q C$ Nashington, D.C. 20545 

NBSIR 78-1559

(1)

\section{AN ASSESSMENT OF HIGH-POWER THYRISTOR TECHNOLOGY}

R. I. Scace

Electron Devices Division

Center for Electronics and Electrical Engineering

National Engineering Laboratory

National Bureau of Standards

Washington, D.C. 20234

October 1978

Final

Prepared for

Department of Energy

Division of Electric Energy Systems

Washington, D.C. 20545

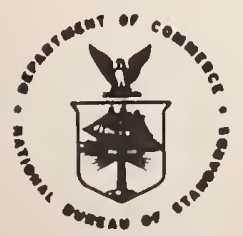

U.S. DEPARTMENT OF COMMERCE, Juanita M. Krops, Secrotary

Dr. Sidney Harman, Under Secrotary

Jordan J. Baruch, Assistant Sacrotary for Science and Technology

NATIONAL BUREAU OF STANDARDS, Emost Ambler, Director 

Abstract . . . . . . . . . . . . . . . . . . . 1

1. Historical Outline . . . . . . . . . . . . . . . I 1

2. Device Design . . . . . . . . . . . . . . . . . 3

2.1 Voltage Blocking Characteristics . . . . . . . . . 3

2.2 Turn-on and Turn-off Mechanisms . . . . . . . . . 5

$2.3 \mathrm{dV} / \mathrm{dt}$ and $\mathrm{dI} / \mathrm{dt}$ Properties . . . . . . . . . . . 7

2.4 Conclusions . . . . . . . . . . . . . . . 9

3. Thermal Problems . . . . . . . . . . . . . . . 10

3.1 Conclusions . . . . . . . . . . . . . . 12

4. Materials Problems . . . . . . . . . . . . . . 13

4.1 Resistivity Nonuniformity . . . . . . . . . . . 13

4.2 Carrier Lifetime . . . . . . . . . . . . . . 14

4.3 Defects... . . . . . . . . . . . . . . 15

4.4 Conclusions . . . . . . . . . . . . . . . 17

5. Processing . . . . . . . . . . . . . . . . 18

5.1 Blocking Junction Formation . . . . . . . . . . . 18

5.2 Blocking Junction Passivation . . . . . . . . . . . 19

5.3 Lifetime Control . . . . . . . . . . . . . 20

5.4 Conclusions . . . . . . . . . . . . . . 22

6. Assembly and Electrical Test . . . . . . . . . . . 22

7. Sumnary . . . . . . . . . . . . . . . . . 24

Acknowledgment . . . . . . . . . . . . . . . . 25

References . . . . . . . . . . . . . . . . . . . 26 
1. Cross-section of a thyristor in the forward-blocking off-state, showing the junction configuration and the depletion layer around junction J2 . . . . . . . . . . . . 33

2. Equipotential lines in a reverse-biased $p^{+}-n$ junction with a contoured surface . . . . . . . . . . . . . . 33

3a. Experimental and theoretical I-V curves for a $1200-V$ triac . . . . . . . . . . . . . . . . . . . 34

3b. Experimental and theoretical $I-V$ curves for a $3500-V$ thyristor . . . . . . . . . . . . . . . . . . . .

3c. Experimental and theoretical I-V curves for a 2500-V thyristor . . . . . . . . . . . . . . . . . .

4. Theoretical curve which illustrates the relative importance of the various physical mechanisms, including heat flow, on the I-V characteristics . . . . . . . . . . . .

5. $p-n-p-n$ device with shorted emitter . . . . . . . . . . . 36

6. A thyristor for double-sided cooling . . . . . . . . . . 36

7. Thyristor with double-sided air-cooled heat sinks . . . . . 37

8. Spreading resistance measurements in silicon slices; distance between measurement points $20 \mu \mathrm{m}$. . . . . . . . . 
An Assessment of High-Power Thyristor Technology

\author{
Robert I. Scace \\ Electron Devices Division \\ National Bureau of Standards \\ washington, DC 20234
}

\begin{abstract}
The current state of the technology for designing and making high-power thyristors is reviewed. The discussion is confined primarily to thyristors having voltage ratings of $2000 \mathrm{~V}$ or greater and current ratings above a few hundred amperes. Particular attention is given to describing the factors which limit the performance of such devices and to discussing recent work aimed at solving these problems.
\end{abstract}

Key Words: High current switches; high voltage switches; SCR; semiconductor devices; semiconductor measurements; silicon devices; silicon controlled rectifiers; solid-state switches; technology assessment; thyristors.

\title{
1. Historical outline
}

The thyristor or silicon controlled rectifier (SCR) was originally devised by Moll et al. at Bell Laboratories [1]. * Its commercial development was undertaken in the mid 1950s by General Electric, followed quickly by a number of other manufacturers. The term thyristor covers a large class of semiconductor devices, all of which characteristically have high and low impedance states. The change from high to low impedance can be initiated by avalanche breakdown of one $p-n$ junction, by control current into an auxiliary electrode, by light, temperature, or other means. Once in the low impedance state, thyristors remain in that condition until the current density through the device falls below some threshold value. At this point, the high impedance state is reestablished. Thyristors may have from two to four terminals and may be composed of from three to five alternating layers of $p$ - and $n$-type

\footnotetext{
* References are.given only to selections from the voluminous literature on thyristors.
} 
conductivity. Some can be switched into the low impedance state for only one direction of current, while others are symmetrical. Strictly speaking, silicon controlled rectifiers are four-layer unidirectional triode thyristors, only one of the class of all thyristors. The discussion here will be concerned entirely with SCRs.

From the beginning, the application of thyristors was primarily at high power levels, since at lower power levels transistors offer the advantages of being able to be modulated and to be returned to a high impedance condition under complete control of the base electrode. The relatively simple structure of the SCR, and the fact that suitable processing techniques were available to produce that structure, led in the early l960s to rapid increases in the size (and therefore the current-carrying capacity) and voltage rating of commercial thyristors. By the mid 1960s, about 10 years after the initial work by Moll, thyristors having voltage ratings of $1000 \mathrm{~V}$ and current handling capacities of over 100 A were beginning to appear.

The Department of the Navy played'a key role in this development by its early recognition that these devices would offer advantages for shipboard power systems. Navy device development programs at both General Electric and Westinghouse during the early and middle 1960s promoted a much more rapid advance of the technology than would otherwise have been possible. Through patent and technology licenses, the know-how from these two companies was relatively quickly transferred to others in both Europe and Japan.

For the most part, the technology was acquired and practiced by companies whose principal business was the manufacture of large electrical equipment. No successful entry into the thyristor business with other than relatively low power devices has been made by any company whose principal business is the manufacture of signal-level semiconductor devices. This is apparently due to two causes. First, electrical equipment manufacturers saw very early the high-power thyris- 
tor as having the potential for becoming an important component for their products. That potential has been realized. Second, the avenues of marketing thyristors and the kinds of application engineering support which the manufacturer gives to his customers were significantly different than those appropriate for more conventional signal-level devices.

The companies listed in table 1 make up the high-power thyristor manufacturing community today. With the exception of National Electronics, Power Semiconductors, and Semikron, all of these firms use their own products extensively in the electrical systems which they manufacture. The three firms just mentioned are companies which specialize in power device manufacture. Nearly all of the companies listed in table 1 also sell their components to equipment manufacturers; only ASEA and Alsthom do not.

\section{Device Design}

A good general reference to the theory and design of thyristors may be found in Gentry et al. [2]. The principles of operation of thyristors, and a few approximations to quantitative design, were well understood in 1964 when their book was published. The rationale for designing devices to withstand a given voltage or to carry a particular current has not changed significantly since then.

However, the development of a complete, quantitative model describing the operation of thyristors in detail is still continuing. The significant technological issues which are currently being addressed will be described in greater detail in the paragraphs to follow.

\subsection{Voltage Blocking Characteristics}

The off-state voitage across a thyristor is supported by a reverse-biased $p-n$ junction. Large thyristors have an essentially plane-parallel junction configuration, as illustrated in figure 1 . The shaded region represents the depletion layer, which is the space surrounding the blocking junction from which essentially all mobile charges have been removed by the applied voltage. 
While figure 1 correctly shows the depletion layer in the interior of the device, it does not show the effects which occur at the perimeter where the junction reaches the surface. These are shown in figure 2, where the surface of a single $p-n$ junction has been beveled in order to spread the depletion layer over a significantly larger distance across the surface than it would otherwise occupy. This must be done because the breakdown electric field in silicon is $230 \mathrm{kV} / \mathrm{cm}$, while in air or in other dielectrics which could be applied to the outside of the silicon the breakdown field is considerably less than that. Beveling reduces the field at the surface and thus reduces the likelihood of arcing across the surface of the device.

The presence of electrical charges or surface states at or near the surface of the silicon also affects the distribution of electric field there. Both the geometrical effects and the influence of surface charge must be taken into account in any analysis to determine the proper contour of the wafer edge to provide stable, reproducible voltage blocking characteristics. Davies and Gentry [3] reported the first efforts toward a solution of this mathematically unpleasant problem. They used a finite-difference method to calculate numerically a potential distribution which satisfied Poisson's equation within the semiconductor and, since they assumed no net charge to exist on or outside the surface of the semiconductor, which satisfied Laplace's equation outside the semiconductor. Once a self-consistent potential distribution was established, the electric field could be determined at any point. Figure 2 is an example of a field distribution computed in this way. Surface bevels of various angles were analyzed, and the results showed that the surface electric field could be reduced (by choice of a suitable bevel angle) to a degree that avoided surface breakdown altogether.

Typically, a 6-deg angle is used on the forward-blocking junction and a 60-deg angle is used on the reverse-blocking junction of presentday thyristors. In a high-voltage device $300 \mathrm{\mu m}$ thick, an annular space 
up to $3 \mathrm{~mm}$ wide is required for such a bevel; this region does not contribute to the current carrying capability of the device. In large devices this significantly reduces the effective area.

Better solutions to this problem are sought. Kao and wolley [4] described a technique for using field-limiting rings to distribute the electric field across the surface of planar high-voltage junctions. An etching technique was described by Temple and Adler [5], and Temple has used ion implantation for this purpose [6]. Each method had its difficulties, and most, if not all, of today's high-power thyristors are made with beveled edges.

\subsection{Turn-on and Turn-off Mechanisms}

An ideal switch would turn on or off instantaneously. Thyristors are not ideal switches, and they often require several tens of microseconds to change their state. The requirements of the more demanding applications have led to a number of investigations aimed at understanding and controlling the turn-on and turn-off mechanisms more precisely. Thyristors switch on only after a period of time which is determined initially by diffusion of minority carriers across the base regions ( $\mathrm{nl}$ and $\mathrm{p} 2$ of fig. 1) of the device. The part of the thyristor nearest the gate electrode connection switches on first, and this condition propagates laterally across the device until, after an additional period of time, the entire thyristor has been switched to its low impedance state.

Until recently, these two turn-on phenomena (initial switching and on-state spreading) were investigated independently because of the complications of calculations in two dimensions [7-10]. More recent work relies heavily on computer analysis [11-14], with the most complete of these studies [14] showing the early stages of turn-on in great detail graphically in three-dimensional computer plots. The model employed in [14] takes into account Shockley-Read-Hall and Auger recombination, band-gap narrowing, and carrier-carrier scattering. Calculations of the on-state voltage drop and power 
dissipation using this model [15] show excellent agreement with experimental results. Figure 3 illustrates this for three different devices, and figure 4 shows the effects of removing various mechanisms from the calculation. In figure 4, the curve labeled "nominal case thermal conductance $(G=50)^{\prime \prime}$ is the same as the curve for the $2500-V$ thyristor in figure 3 .

Turn-off begins at the time when the current in the device falls below the holding current, which may be $100 \mathrm{~mA}$ or less for a 100-A rms-rated thyristor. (The decrease in current is entirely a function of the circuit of which the thyristor is a part.) At this instant, the depletion region about $\mathrm{Jl}$ of figure 1 begins to be established, if it is assumed that the thyristor is entering the reverse-blocking condition. The excess charge carriers (electrons in $\mathrm{pl}$, holes in $\mathrm{nl}$ ) must be removed before the depletion layer can expand. This removal is accomplished mainly by recombination, at a rate determined by the minority-carrier lifetimes in regions $\mathrm{nl}$ and $\mathrm{pl}$.

High-power thyristors require careful control of minority-carrier lifetime if their performance is to be optimized. In addition to affecting both turn-on and turn-off behavior as mentioned above, the lifetime significantly influences reverse leakage currents, dI/dt characteristics*, on-state voltage drop, and trigger sensitivity. Unfortunately, the measurement of lifetime as a function of position in solid-state devices is one of the most difficult to perform. Recent measurements of lifetime on charge-carrier concentration in cross-sections of thyristors have been made using electron irradiation [6], the recombination radiation at $1.1 \mu \mathrm{m}$ [17], and free-carrier absorption of laser radiation at $3.4 \mu \mathrm{m}$ [18]. Specially prepared devices are required to make measurements by all of these techniques.

*This property, although related to turn-on, is specified separately from turn-on time. A discussion of dI/dt characteristics is given in the following section. 
None of these measurement methods is as yet adaptable to day-to-day production-line use. If the distribution of carriers within operating thyristors can be determined, local lifetime and diffusion length data can be deduced. These data can then be used in computer models from which improved device designs can be developed.

More information is needed about the detailed properties of recombination centers in thyristors. Some of this knowledge can be obtained by thermally stimulated current and capacitance measurements. The temperature dependence of the capture cross-sections of recombination centers is not known in many cases, and evidence exists [19] for a recombination center of unknown origin with a ratio of highlevel to low-level lifetime of greater than 12. For comparison, the ratio for gold is 4 [16]. A high ratio is desirable to improve the trade-off between short turn-off time and low on-state voltage drop. With today's computer models providing improved understanding of the role of lifetime as a function of position in the operation of thyristors, the realization of improved devices must then depend upon the development of processing techniques which permit precise tailoring of lifetime within the device to meet the requirements of the models and upon the development of suitable means to measure the resulting lifetime as a function of position to verify that the desired lifetime distribution has been achieved.

\section{3 dV/dt and dI/dt Properties}

In many applications, thyristors in the off-state are exposed to high rates of rise of applied forward voltage. This is particularly true in inverter circuits where waveforms are frequentl: not sinusoidal. If no design precautions are taken, the charge displaced from the forward blocking junction as the depletion layer widens can cause the current density in the device to exceed the threshold for switching, and the device will turn on in the absence of a gate trigger signal. This effect is controlled by the use of the shorted emitter [20]. 
As figure 5 shows, both the emitter $n$-region (n2) below the cathode terminal and the neighboring p-region ( $p 2$ ) are connected to the cathode terminal. Emitter junction $\mathrm{J} 3$ is thereby short-circuited, and these emitter shorts provide a path for the displaced charge in the upper p-region ( $\mathrm{p} 2$ ) to pass to the cathode terminal without crossing the cathode emitter junction. It also may be seen that a considerable lateral current in the p-base exists as a result. In effect, the emitter efficiency is made to be zero at low current densities, but as the lateral current develops an appreciable voltage drop in the p-region, the portions of the emitter farthest from the shorts become forward biased and normal electron injection can take place. At high current densities, the emitter efficiency is high, being little affected by the shorts. The shorts consume a small portion of the active area, commonly a few percent, and do not appreciably decrease the current-handling capabilities of the device. Since this dV/dt effect can be isolated from the remainder of the device design, early analytical attempts at understanding and solving the design problem were reasonably successful [21]. This early analysis neglected the effects of conductivity modulation and the fact that the emitter efficiency is not unity, complications which would have made an analytical solution impossible. These can, of course, be modeled successfully on today's computer models.

A much more difficult problem relates to the limitations on current-handling capability during the early stages after the device has been switched on. As briefly mentioned above, a small region near the gate electrode switches into the conducting state first, and this condition then spreads laterally across the device at a speed of approximately $50 \mathrm{~m} / \mathrm{s}$ [22] until the device is completely turned on. The spreading velocity of the turned-on region is a function of the current density, the temperature, the distribution of emitter shorts, the sheet resistance of the bases ( $n 1$ and $p 2$ in fig. 5) and the distribution of recombination centers. 
Since only a fraction of the area of the device is turned on for some time following triggering, the current-carrying capability of the thyristor during that interval is limited. The maximum rate of current rise which the device can handle repetitively and the peak pulsecurrent rating are functions of time; both are dependent upon the spread of the turned-on region. Numerical and experimental analyses of the pulse-current rating of thyristors during this period show that junction temperatures in excess of $1000^{\circ} \mathrm{C}$ exist during pulses having durations in the range of 10 to $100 \mu s$ [24]. Evidently these very high instantaneous temperatures do not have an adverse effect on the device.

The studies referred to in this section have provided at least the minimal understanding required for the development of specialpurpose firing arrangements. Devices have been designed to have especially high or low sensitivity to gate triggering, to have a gate amplifying region to turn on a larger area soon after firing to improve $d I / d t$ characteristics, or to be triggered by light [25-28] . Light-triggered devices offer attractive advantages for high-voltage dc terminal (HVDC) systems, in part because the trigger source can be at ground potential while the thyristor is at a potential of tens or hundreds of kilovolts. The design of such devices requires a difficult trade-off to be made, since high sensitivity to light but low sensitivity to $\mathrm{dV} / \mathrm{dt}$ effects must exist concurrently, and additional information on the details of gate-region operation appears to be needed before these trade-offs can be optimized.

\subsection{Conclusions}

Many design questions which could only be dealt with empirically a few years ago can now be answered quantitatively with the aid of computer models. Design of a thyristor for a specific application requires that trade-offs be made. For example, higher voltage ratings require reduced current ratings for a given diameter of device, since the on-state voltage drop must be increased. Higher $\mathrm{dV} / \mathrm{dt}$ ratings require further sacrifice of current rating, because 
emitter shorts reduce the active area of the device. In some cases, the optimum set of trade-offs for a given application may raise the cost of the thyristor itself in order to permit savings to be made elsewhere in the equipment.

A new generation of questions can now be posed, such as:

Can current ratings for one line-frequency period or less (surge current) be improved in comparison with steady-state ratings?

Considering that substantial lateral currents exist inside thyristors, can these be employed to cause the on-state to spread more rapidly and thus improve dI/dt ratings?

Are there other means to improve dI/dt?

If one could arbitrarily control minority carrier lifetime locally. within the device, what beneficial effects could be expected?

As experience is gained in the use of models, such questions could profitably be explored. Intuition and empiricism are not adequate to deal with the quantitative behavior of such an apparently simple but, in fact, very complex device.

\section{Thermal Problems}

The ratings of high-power semiconductor devices in general are limited by problems of heat removal. The steady-state power dissipation of a 50-mm diameter thyristor is comparable to that of an electric range burner on high heat [15]. An appreciation of the thermal problem can be gained when one considers that this quantity of heat must be removed from the thyristor while limiting the maximum steady-state junction temperature to $125^{\circ} \mathrm{C}$. Most devices larger than $30 \mathrm{~mm}$ in diameter, and all larger than $50 \mathrm{~mm}$, are enclosed in packages which provide for the extraction of heat from both sides of the device. Figure 6 shows a typical design of such an assembly in cross-section, at approximately full scale. Figure 7 shows how this assembly is incorporated into a further assembly for exchange of heat into an air stream. 
The double-sided cooling approach was taken in response to the heat dissipation problems encountered with stud-mounted packages when devices passed about $25 \mathrm{~mm}$ in diameter in the mid 1960s [29].

Not only did the improved cooling allow an increase in the current rating of the device for a given size, but a thermal expansion problem was alleviated. The thermal expansion coefficient of silicon is significantly lower than that of copper and is matched within a factor of 2 by only two metals, tungsten and molybdenum, as table 2 shows. The thyristor element (see fig. 6, part 2) is composed of a metallurgically bonded sandwich of silicon with a tungsten or molybdenum plate one or two millimeters thick on either side.

In previous designs, this sandwich subassembly was bonded to a copper stud, usually with a brazing alloy having a high shear strength. Upon cooling from the brazing temperature, the copper contracted more than the adjoining metal plate, and much more than the silicon. The stresses thus created frequently caused the brittle silicon to crack, destroying the device. The two-sided assembly provides for pressure contacts between the copper conductors (fig. 6, part 3) and the thyristor subassembly. Lateral differential expansion can be accommodated by sliding at the pressure contacts, thus reducing the stresses on the silicon.

With today's larger thyristors the differential expansion problem has returned, but now the difference between the thermal expansion coefficients of silicon and tungsten (ormolybdenum) is the source of stress. The sandwich of silicon and the two refractory metal plates is not symmetrical; the cathode plate is smaller in diameter than the anode plate because the periphery of the silicon has been beveled. As the diameter of the device increases, the total dimensional mismatch between the silicon and the metals increases, sufficiently: increasing the bending moments on the assembly that fracture of the silicon can occur. If the assembly is to remain flat, the metal members must be increased in thickness to a centimeter or more. Since neither tungsten nor molybdenum has a thermal conductivity as high as 
copper, this causes a thermal conductivity penalty to be paid. Furthermore, both tungsten and molybdenum are expensive. In present-day large thyristors these back-up plates frequently cost more than the silicon.

In a different design approach now being taken to overcome this problem, the silicon is not attached to any back-up plate. Thin (1- to 2-mm) tungsten or molybdenum plates between the silicon and the copper conductors are used in a package like that of figure 6 , but none of these pieces is metallurgically bonded to its neighbors. The thermal expansion problem is alleviated, because each of these joints permits sliding to take place to accommodate differences in dimensions. There are two problems with this approach. One is that the number of dry interfaces which have relatively large thermal impedance is now doubled. With the sandwich construction, the interfaces between the copper conductors of figure 6 and the thyristor element were the only dry joints. With the new design, there is also a dry joint between the silicon and each back-up plate. The second problem lies in the fact that the silicon slice is completely unsupported during manufacture. Silicon is as brittle as glass, and these slices are fragile. Extreme precautions must be taken in handling to avoid breakage.

One further problem exists with two-sided cooling assemblies. The electrical and thermal paths between the heat sinks and the device and the dry interfaces within the device package are all held together by an externally applied force. The force, about $70 \mathrm{~kg} / \mathrm{cm}^{2}\left(1000 \mathrm{lb} / \mathrm{in}^{2}\right)$, is generally provided by heavy springs in an external framework. The structure adds cost and size to the assembly. In many applications, the increased size presents problems.

\subsection{Conclusions}

Heat management will continue to be a major design consideration for thyristors. Exotic methods for heat removal, such as heat pipes or the use of the very few materials having thermal conductivities greater than that of copper (e.g., type II B diamond), cannot often be 
used, either because they are far too costly or for basic physical reasons. The thermal flux from the silicon slice is typically $300 \mathrm{w} / \mathrm{cm}^{2}$, three times the flux at which water cooling can be used.* It is necessary to transport the heat to a surface of larger area to reduce the heat flux to a more tractable level, and solid copper is the best practical medium for this purpose. It appears that no significant breakthrough is possible in this direction.

\section{Materials Problems}

The upper limits of thyristor ratings have historically been imposed by the characteristics of available float-zoned silicon. Applications for very large devices have always been sufficient in number that, with every advance in float-zoned crystal technology, new thyristor generations have appeared. For example, the largest diameter thyristor which has been publicly announced is made by Mitsubishi, with a rating of $4000 \mathrm{~V}, 2500 \mathrm{~A}$. This device is made from a 100-mm diameter slice of silicon, which is commercially available on a pilot basis only from Wacker Chemitronic in Germany. This section deals with those properties of today's silicon which impose significant limitations on high-power thyristor performance.

\subsection{Resistivity Nonuniformity}

Many thyristor properties depend critically on the characteristics of the starting silicon. Although semiconductor-grade silicon is an extraordinarily pure material, there are trace quantities of impurities present which were not deliberately introduced during the crystal growing process. Oxygen is present in relatively high quantities in Czochralski silicon; its concentration is much lower in float-zoned silicon. Under certain conditions of heat treatment, otherwise electrically inactive oxygen can form groupings within the

*At about $100 \mathrm{~W} / \mathrm{cm}^{2}$ a film of water vapor develops, separating the liquid from the solid surface. This gaseous layer radically increases the thermal impedance. 
silicon crystal which add electrons in an uncontrolled fashion and thus affect the resistivity [30]. Vacancies in the silicon lattice (places in the silicon lattice where no atom is present) are essential to the process of oxygen donor formation. Because of the importance of resistivity control in thyristor manufacture, if the designed properties of the device are to be realized, oxygen must be held to a low level in the silicon crystal at all stages of manufacture.

Until recent years, float-zoned silicon has characteristically had a variation of resistivity from the center of the slice to the periphery of as much as $50 \%$. Since the blocking voltage limit of a $p-n$ junction depends on the lowest resistivity anywhere in the junction area, this meant that the nominal resistivity of the silicon and the nominal design voltage had to be much higher than required by theory for the actual voltages achieved. With the advent of neutron-transmutationdoped (NTD) silicon [31-34], thyristors can be produced with at least 15\% higher blocking voltage ratings without changing the processing in any way. This change is attributable entirely to the increased uniformity of resistivity across the diameter of the starting silicon slice. This improved unformity is noticed not only on a large scale, but also in the fine details of resistivity as shown in figure 8 . These fine-scale variations in resistivity (striations) have been shown to cause irregularities in the profile of high voltage $p-n$ junctions $[35,36]$. Such irregularity leads to increases in the local electric field and to decreased breakdown voltage.

\subsection{Carrier Lifetime}

The minority-carrier lifetime of conventional float-zoned silicon has been more than sufficient for high-voltage thyristor use for at least ten years. Minimum values in the neighborhood of $200 \mu \mathrm{s}$ are generally specified when material is purchased and values of $1 \mathrm{~ms}$ or - greater are typical of as-grown material. In order to maintain low on-state voltage drops, the charge-carrier lifetime in the completed device must be kept relatively high-[37]. With suitable care taken 
during processing, values of several tens of microseconds usually exist within the completed device. Only when this must be sacrificed to improve the switching speed of the device are deliberate steps taken to reduce the lifetime [38]. Discussion of ways in which this is done will be found in a later section.

For NTD silicon, the situation is different. During irradiation in the nuclear reactor, the silicon crystal structure is considerably disarranged $[31,32]$, and the electrical properties of the material are changed drastically. In order to return the resistivity and lifetime to useful values, the crystal must be annealed. The annealing process has been studied by a number of workers in recent years [39-42]. The resistivity value stabilizes after an anneal of less than $1 \mathrm{~h}$ at $500^{\circ} \mathrm{C}$, whereas the lifetime reaches its final value only after annealing at temperatures of $800^{\circ} \mathrm{C}$ or higher. The lifetime recovery appears to depend significantly on the cleaning procedure used after the crystal has been irradiated and before it has been annealed. Lifetimes of 50 to 100 us can be achieved by this means. These values appear adequate, even though they are substantially less than the lifetime in typical float-zoned silicon. Some improvement in NTD annealed lifetime can be expected as more is learned about making NTD silicon and its annealing mechanisms.

\subsection{Defects}

Because of the large scale of their structure, power thyristars are not as sensitive in processing to some small-scale surface defects which would cause great difficulty in integrated circuit processing. However, the residual impurity levels (particularly of heavy metals, oxygen, and carbon) must be closely controlled. Structural defects appear to serve as nucleation sites for clusters of random impurities, which then can influence the distribution of the electric field in the depletion and lead to reduced voltage breakdown characteristics. 
Elements such as iron, copper, nickel, and other heavy metals have been found to affect the minority carrier lifetime and to increase the reverse-biased leakage current of $p-n$ junctions. These elements probably are incorporated during the device manufacturing process and can be controlled by maintaining suitably clean conditions. Most of these stray impurities have been observed to collect preferentially in the neighborhood of dislocations or other crystal imperfections where the lattice distortions permit them to be more soluble. Careful hightemperature processing techniques reduce the incidence of processinduced structural imperfections in the silicon and thus tend to reduce the effects of the presence of these random impurities.

Carbon has long been known to be present in semiconductor silicon at levels sometimes exceeding a few parts per million*. Since carbon (like silicon) is tetravalent, the assumption was generally made that it was incorporated in the silicon lattice substitutionally and contributed no electrical effects. It was regarded as an analog of a silicon atom. In the last few years, high concentrations of carbon have been discovered to correlate well with the existence of striations in the crystal as well as with precipitates of $\alpha$-quartz and $\gamma-\mathrm{Fe}_{2} \mathrm{O}_{3}$ [43] The presence of these precipitates is of course undesirable, and their distribution is found to be quite nonuniform within the crystal. It is postulated that the presence of carbon, which was grown into the crystal, produces lattice strains which promote the formation of these precipitates by diffusion of other impurities within the crystal in such a manner as to relieve the carbon-induced strain. The nonuniform distribution of carbon has also been shown to lead to nonuniform concentrations of gold which had been introduced to control lifetime if the average density of carbon is greater than $10^{16} \mathrm{~cm}^{-3}$. This implies that the lifetime from point to point within the device will vary in an

\footnotetext{
*One part per million in silicon equals $5 \times 10^{16}$ atoms per cubic centimeter.
} 
uncontrolled manner. The same workers found that carbon levels of about $10^{17} \mathrm{~cm}^{-3}$ cause rounded reverse blocking characteristics and that carbon in amounts even below $5 \times 10^{16} \mathrm{~cm}^{-3}$ caused problems in annealing of NTD silicon.

Studies of the effects of unwanted impurities and the mechanisms by which these effects arise are made particularly troublesome by the very low concentrations at which they are significant. It is desirable to detect the presence of such impurities as oxygen and carbon at levels well below $10^{16} \mathrm{~cm}^{-3}$, but at present this is only marginally possible. Infrared transmission measurements have been widely used for this, but thick specimens are required. Device wafers cannot be used because they are too thin. Transmission electron microscopy and electron resonance techniques are used for studying radiation-induced defects in NTD silicon and the many precipitation products which can occur. Thermally stimulated current and capacitance techniques are in use to develop a collection of signatures of various deep-level defects in silicon. In principle, such a catalog could be used to identify unwanted defects to aid in process control. A good review of currently available measurement technology is given in reference [45]. The inability to observe and measure imperfections and impurity levels at extremely low values has been and continues to be a limitation in understanding and controlling the effects of such defects.

\subsection{Conclusions}

The ability to make devices at good yields that perform according to their design is limited by the presence of a variety of structural defects and unwanted impurities which are either present in the silicon slice or are put there during wafer processing operations. The very low concentrations at which these defects are significant causes great difficulty in their detection and control. In many cases, the detailed mechanisms by which these defects act to limit the performance of the device are not known. 


\section{Processing}

This section will not present a complete description of the process for making high power thyristors but will discuss certain steps in which difficulties occur. Manufacturing processes for these devices employ many of the same techniques used for making integrated circuits, but the scale of the operations is frequently quite different. Therefore, the problems which are encountered tend to be unique to the manufacture of high power devices. Furthermore, the discussion is not intended to describe the process used by any particular manufacturer but to be representative of such processes. Details of processes for producing the desired junction configuration in the silicon wafer and for assembling the wafer into its final housing are regarded as proprietary, and little published literature exists on these topics.

It should be noted that several processes which are in wide use for making other kinds of semiconductors are rarely used in making high-power thyristors. Such techniques as epitaxial growth, ion implantation, and planar blocking junctions have been tried for experimental devices but have so far not been found to be useful in highvoltage, high-current thyristors for both economic and technical reasons.

\subsection{Blocking Junction Formation}

The first diffusion step, in which the high-voltage blocking junctions ( $\mathrm{Jl}$ and $\mathrm{J} 2$ of $\mathrm{fig}$. 1) are formed, is crucial to obtaining the desired voltage rating of the finished thyristor. The breakdown voltage rating of the blocking junctions is directly related to the resistivity of the starting silicon and to the gradient of the impurity concentration at the junction. High voltage requires high resistivity silicon (100 to $200 \Omega \cdot \mathrm{cm}$ ) and a shallow doping gradient, which implies a deep junction diffusion. Junction depths of 75 to $100 \mu \mathrm{m}$ are common. This requires long diffusion times (up to $100 \mathrm{~h}$ ) and high temperatures, usually $1250^{\circ} \mathrm{C}$; gallium and aluminum are commonly used for the diffusing species. It is important that no crystal damage, such as dislocations, be introduced by this diffusion process and also that extreme cleanliness be maintained to avoid reducing the minority-carrier lifetime in 
the silicon by inadvertent introduction of contaminating elements.

Several gettering methods are used to help reduce the effects of stray contaminants. The silicon slices may be given a lapped surface before diffusion. If this is done properly, this surface will develop a superficial network of dislocations which does not penetrate the silicon appreciably, but in which unwanted elements are more soluble. Or, the diffusion conditions may be such that a thin liquidus exists on the surface, in which the random impurities are more soluble. After diffusion, the outer region is etched away.

If it is found that the junction breakdown voltage is too low or that reverse leakage currents are too high after diffusion, there are no tests that can be used in a production environment available to determine the cause of the problem. Some feeling for the sensitivity required of such tests can be gained from the following: One cubic centimeter of silicon contains $5 \times 10^{22}$ atoms, and if it is $n$-type with a resistivity of $200 \Omega \cdot \mathrm{cm}$, then $2.5 \times 10^{13}$ of those atoms have been replaced with donor impurities. The donor concentration is thus one-half part per billion. Significant stray impurity concentration levels are comparable.

In the event of trouble, one would like to identify the kind of the defect and its concentration as an aid to finding its source and correcting the difficulty. The lack of suitable measurement techniques means that much process control and correction in thyristor manufacturing is empirical. Very likely much of the gettering of wafers is done purely as a safety measure and may not really be necessary. Empiricism and unnecessary process steps are costly. It is expected that work on thermally stimulated current now being undertaken will help relieve this process control problem.

\subsection{Blocking Junction Passivation}

After all high-temperature processing has been done and the wafer edge has been contoured and etched, the freshly etched edge of the wafer must be protected against subsequent contamination by some kind of dielectric coating. Further, as described earlier, this region 
is exposed to extremely high electric fields which would break down any gaseous environment. It would be desirable to have a reproducible, inorganic coating applied to the surface. Success in finding such a material and a suitable process for applying it has been extremely limited. One requires a material (perhaps a glass) which can be applied at a temperature sufficiently low that the metal-silicon contacts are not affected, which contains no ingredients which would adversely affect characteristics of the $p-n$ junction, which is impervious to moisture or other deleterious fluids, and which has a reproducible amount of electric charge within it. This last characteristic affects the interface state density at the surface of the silicon and strongly influences the distribution of the electric field at the boundary between the silicon and the insulating film. Lacking such an inorganic passivating layer, most manufacturers use a silicone rubber compound. With sufficient care in characterizing the silicone rubber and in applying it, reasonably reproducible results can be obtained. This step remains one of the least understood and poorest controlled steps in the manufacture of these devices, since it is based on empirical methods only.

\subsection{Lifetime Control}

Nothing so far has been said about the means of controlling the minority-carrier lifetime within the device to any specific value. -Thyristors for line frequency operation frequently do not require any lifetime-controlling steps to be taken. Devices which are to operate at higher frequency generally do. Unless specific steps are taken, a large thyristor may take several tens of microseconds to turn off after the current, through it decreases to zero. In increasing numbers of applications, thyristors are required to turn off more rapidly and specific steps to control the lifetime must be taken. Two techniques. are in general use, diffusion of a lifetime-controlling impurity and irradiation with electrons or gamma rays.

Gold [46], and to a lesser extent platinum [47], are the impurities generally used for lifetime control by diffusion. This diffusion 
follows the emitter diffusion and precedes the contact metallization steps. This operation is difficult to control, because one does not know the lifetime in the device at that stage. Before the lifetimecontrolling diffusion is done, one needs to know how much additional lifetime-controlling impurity to add to achieve the desired result. Too much gold, for instance, will raise junction leakage currents to an intolerable degree and adversely affect the conducting voltage drop. Too little gold will fail to reduce the lifetime to the desired level.

The way this problem is dealt with in practice is to select a sample of a few wafers from a processing lot, give them a diffusion for lifetime control under conditions based on experience, and then complete the processing of the samples (metallization, backup plate attachment, beveling, and passivation) so that their turnoff time can be measured. The remainder of the lot is held aside until the results of the measurement on the sample are available. Then a final selection of the conditions for the lifetime-controlling diffusion is made and the balance of the lot is processed.

There are obvious disadvantages to this procedure. The main part of the lot is delayed, which adds to the cost of inventory. It is assumed that the lot is uniform enough that the samples are representative, and that the process is under sufficient control that the diffusion on the sample and then the diffusion of the main lot will behave in the same way, even if a period of a few days or weeks has elapsed. It would be far better to have a way of measuring lifetime or another parameter correlated with turn-off time prior to the lifetime-controlling diffusion, but the means to do this are not available.

Radiation techniques [48, 49] for lifetime adjustment offer the advantage that the electrical properties of the device can be determined before irradiation and the radiation dose tailored to produce more accurately the desired control over lifetime. For this reason, radiation is being used more frequently today than in the past, in spite of the industry's relatively limited experience with it. One disadvantage to radiation control of lifetime is that the facilities to do this are 
not available in most semiconductor manufacturing houses, due to the expense and the problems of managing a radioactive facility. One is therefore faced with the problem of moving semi-finished, expensive materials to another place, frequently under the control of others, for a critical process step.

\subsection{Conclusions}

Development is continuing on refinements of the shape of the edge of the wafer to control surface electric fields without undue sacrifice of current-carrying area. Major efforts are required to reduce the empiricism now needed for effective passivation of the blocking junctions around the periphery of the device and for the execution of lifetime-controlling diffusion. Large cost improvements could result from reduction of the need for a hermetic external package. Much-improved precision in process control would pay large dividends especially in the manufacture of thyristors for HVDC equipment. The design specifications for these devices have very tight tolerances imposed by the need for proper current and voltage sharing among hundreds of series-parallel connected thyristors. Improved in-process measurement will improve yields and thus reduce thyristor costs which comprise a large part of the cost of HVDC terminals.

\section{Assembly and Electrical Test}

Because the blocking junctions are passivated with a material which is not impervious to water, the thyristor subassembly is packaged in. a hermetic housing. This is a relatively complex metal and ceramic assembly, providing for high-current electrical connections and largearea thermal connections as previously described. In addition, arrangements must be made for a low-current connection for the gate signal. The final seal for the assembly is done by a peripheral weld, joining two metal flanges together. This can be done either as a copper compression weld or by a helium arc-welding process. Two problems exist. First, the assembly must be truly hermetic. Thyristors are used in industrial equipment with a design life of many years. One function of the hermetic housina is to maintain a dry, contaminant-free 
environment for the thyristor element itself. Since a typical device housing may contain a half-dozen independently made joints, the chances of occurrence of a leak are considerable. Subassemblies of the housing must be checked by helium mass spectrometry for freedom from leaks, and the finished assembly must be checked as well. The assurance of hermeticity has always been a difficult problem in the semiconductor industry.

The second problem is that of cost. The housing is made of a precisely formed high-alumina ceramic, nickel-iron parts, and copper contact pieces. If it were possible to find a suitable inorganic junction-coating material such as that described in section 5 , the large and expensive housing would not be required; a molded plastic encapsulation could be devised which would be suitable. At present, this is not the case, and a silicon wafer which, in its finished form, is worth a few tens of dollars is the active part of an assembly whose cost is a few hundred dollars.

Electrical characterization of high power thyristors is described in Chapter 4 of reference [2]. These principles have not changed.significantly, but the body of data gathered from field experience, which is useful to determine the applicability of these characterization methods, has grown [50]. Work on improving the techniques of characterizing thyristors is continuing, particularly with respect to thermal [51, 52] and electrical [53] transients which are important in large systems.

With the continuing increase in the size and power-handling capability of thyristors, the magnitude of the investment in test equipment has increased substantially. Equipment to test these devices is all custom designed and is therefore expensive. In evaluating a new device design, a large number of specimens must be tested to destruction. This is also costly. There are no adequate predictors of life, so devices must be tested under maximum rated conditions for long periods to be sure that no failure mechanism is present which will cause the life of the device to fall short of the equipment design life. 
At present, there seems little prospect that techniques of product evaluation and quality control will change significantly in the future.

\section{Summary}

The state of the art of high power thyristor technology has been reviewed. In recent years, three principal developments have spurred the development of these devices to voltage and current levels significantly above those existing previously. These are:

a) the development of neutron-transmutation-doped silicon as a comercial material;

b) improved, but still incomplete, understanding of the sources of defects in silicon, including the formation of oxygen donors, the association of carbon with striations in silicon, and the role of carbon in the formation of precipitates of other impurities; and,

c) most significantly, the development of detailed computer models which permit the analysis of existing devices and the design of new ones with a degree of accuracy impossible until only recently.

None of the above advances can be considered as finished work, but they are significant developments over the state of knowledge of, say, a half-decade ago.

Many problems remain. In device design, the use of the most advanced computer models remains within those firms which have developed them; the availability of these tools to the device manufacturing industry is by no means uniform. The models need to be applied to the design of advanced gating arrangements, such as optically sensitive ones, where the available energy to stimulate the thyristor is limited and where (in HVDC) the thyristor's other characteristics cannot be traded off in favor of high gate sensitivity. Improved thyristor performance can be obtained by reducing the thermal impedance of the cooling arrangements.

The next step in thyristor current ratings awaits the more general 
availability of high-quality 100-mm diameter silicon. The level of carbon in all float-zoned silicon must be reduced and its distribution in the crystal made more uniform. The lifetime of NTD silicon must be raised and the annealing mechanisms understood more completely.

Processing improvements revolve principally around the removal of empiricism as a process control tool. The control of process-induced defects and unwanted impurities, the techniques of lifetime control, and the passivation of the blocking junctions all would be improved if more objective techniques were available. Significant package cost reduction also requires advancement in passivation methods.

Many of these problems will yield only with the aid of new or improved measurement techniques. Methods are needed for the detection and identification of the whole spectrum of defects: crystalline imperfections down to single-atom vacancies, unwanted elements (especially carbon), and precipitates of various kinds. Better means of lifetime control can only be developed if new lifetime measurement tools are available, preferably with good spatial resolution. Measurement methods which are useful not only in the laboratory but in a factory environment are of great potential value.

It is particularly desirable from a national viewpoint to have new measurement technology available uniformly to the entire industry. Because of this fact, and also because the resources needed for this kind of development exist in only a few of the largest firms in the industry (whose motivation to develop new measurement technology has been rather modest in the past), it seems appropriate to consider a significant governmental role in the development of the needed measurement tools.

\section{Acknowledgment}

Figures 3, 4, and 8 are reproduced by permission of the Institute of Electrical and Electronics Engineers, Inc. W. M. Bullis and F. F. Oettinger provided a number of helpful and welcome suggestions for improvement of this study. 
1. Moll, J. L., Tanenbaum, M., Goldey, J. M. and Holonyak, N., Jr., $p-n-p-n$ Transistor Switches, Proc. IRE 44, 1174-1182 (1952).

2. Gentry, F. E., Gutzwiller, F. W., Holonyak, N., Jr., and Von Zastrow, E. E. , Semiconductor Controlled Rectifiers: Principles and Applications of $p-n-p-n$ Devices, Prentice Hall, Inc., Englewood Cliffs, N.J., 1964.

3. Davies, R. L. and Gentry, F. E., Control of Electric Field at the Surface of $p-n$ Junctions, IEEE Trans. Electron Devices ED-11, 313-323 (1964).

4. Kao, Y. C. and Wolley, E. D., High-Voltage Planar $p-n$ Junctions, Proc. IEEE 55, 1409-1414 (1967).

5. Temple, V. A. K., and Adler, M. S., A Simple Etch Contour for Near Ideal Breakdown Voltage in Plane and Planar $p-n$ Junctions, Technical Digest, 1975 International Electron Devices Meeting, Washington, DC, December 1-3, 1975, pp. 171-174.

6. Temple, V. A. K., Junction Termination Extension (JTE), A New Technique for Increasing Avalanche Breakdown Voltage and Controlling Surface Electric Fields in $p-n$ Junctions, Technical Digest, 1977 International Electron Devices Meeting, Washington, DC, Decenber 5-7, 1977, pp. 423-426.

7. Hubner, K., Melehy, M., and Biesele, R. L., Uniform Turn-on in Four-layer Diodes, IRE Trans. Electron Devices ED-8, 461-464 (1961).

8. Bergman, G. D., The Gate-Triggered Turn-on Process in Thyristors, Solid-State Electronics $\underline{8}, 757-765$ (1965).

9. Dodson, W. H. and Longini, R. L., Probed Determination of Turn-on Spread of Large Area Thyristors, IEEE Trans. Electron Devices ED-13, 478-484 (1966).

10. Davies, R. L. and Petruzella, J., $p-n-p-n$ Charge Dynamics, Proc. IEEE 55, 1318-1330 (1967).

11. Anheier, W., Engl, W. L., Manck, O., and Wieder, A. W., Rigorous Numerical Analysis of a Planar Thyristor, Technical Digest, 1975 International Electron Devices Meeting, Washington, D.C., December $1-3,1975$, pp. 363-366.

12. Dännhauser, F., and Voss, P., A Quasi-Stationary Treatment of the Turn-on Delay Phase of One-Dimensional Thyristors, Part I - Theory and Part II - Experiments, IEEE Trans. Electron Devices ED-23, 928-936 and 936-939 (1976). 
13. Anheier, W., Engl, W. L., and Sittig, R., Numerical Analysis of Gate-Triggered SCR Turn-on Transients, Technical Digest, 1977 International Electron Devices Meeting, Washington, D.C., December $5-7,1977$, pp. 303A-303D.

14. Adler, M. S. and Temple, V. A. K., The Dynamics of the Thyristor Turn-on Process, Technical Digest, 1977 International Electron Devices Meeting, Washington, D.C., December 5-7, 1977, pp. 300-303.

15. Adler, M. S., Accurate Calculations of the Forward Drop and Power Dissipation in Thyristors, IEEE Trans. Electron Devices ED-25, 16-22 (1978).

16. Zimmerman, W., Measurement of Spatial Variations of the Carrier Lifetime in Silicon Power Devices, Physica Status Solidi [a] 12, $671-678,1972$.

17. Silber, D. and Maeder, H., The Effect of Gold Concentration Gradients on Thyristor Switching Properties, IEEE Trans. Electron Devices ED-23, 366-363 (1976).

18. Houston, D. E., Krishna, S., and wolley, E. D., Study of Charge Dynamics in High Speed Power Devices Using Free Carrier Absorption Measurements, Technical Digest, 1976 International Electron Devices Meeting, Washington, D.C., December 6-8, 1976, pp. 504-507.

19. Cornu, J., Sittig, R., and Zimmerman, W., Analysis and Measurement of Carrier Lifetimes in the Various Operating Modes of Power Devices, Solid-State Electronics 17, 1099-1106 (1974).

20. Aldrich, R. W. and Holonyak, N., Jr., Two-Terminal Asymmetrical and Symmetrical Silicon Negative Resistance Switches, J. Appl, Phys. 30, 1819-1824 (1959).

21. Gentry, F. E., Scace, R. I., and Flowers, J. K., Bidirectional Triode $p-n-p-n$ Switches, Proc. IEEE 53, 355-369 (1965).

22. Ruhl, H. J., Jr., Spreading Velocity of the Active Area Boundary in a Thyristor, IEEE Trans. Electron Devices ED-17, 672-680 (1970).

23. Somos, I., and Piccone, D. E., Plasma Spread in High-Power Thyristors Under Static and Dynamic Conditions, IEEE Trans. Electron Devices ED-17, 680-687 (1970).

24. Ikeda, S., Tsuda, S., and Waki, Y., The Current Pulse Ratings of Thyristors, IEEE Trans. Electron Devices ED-17, 690-693 (1970).

25. Silber, D., Winter, W., and Fullmann, M., Progress in Light Activated Power Thyristors, IEEE Trans. Electron Devices ED-23. 899-904 (1976). 
26. Temple, V. A. K., Directly Light-Fired Thyristors With High di/dt Capability, Technical Digest, 1977 International Electron Devices Meeting, Washington, D.C., December 5-7, 1977, pp. 22-25.

27. DeBruyne, P. and Sittig, R., Light Sensitive Structure for High Voltage Thyristors, PESC 76 Record, IEEE Power Electronics Specialists Conference 1976, Cleveland, OH, June 8-10, 1976, pp. $262-266$.

28. Schlegel, , E. S. and Page, D. J., A High-Power Light-Activated Thyristor, Technical Digest, 1976 International Electron Devices Meeting, Washington, D.C., December 6-8, 1976, pp. 483-486.

29. Nowalk, T. P., Ferree, H. E. and New, T.C.T., Flat Packaged Thyristor Assembly for High-Voltage Application, Proc. IEEE 55, 1434-1440 (1967).

30. Helmreich, D., and Sirtl, E., Oxygen in Silicon: A Modern View, Semiconductor Silicon/1977, H. R. Huff and E. Sirtl, Eds., pp. 626-636 (Electrochemical Society, Inc., Princeton, N.J., May 1977).

31. Janus, H. M., and Malmros, O., Application of Thermal Neutron Irradiation for Large Scale Production of Homogeneous Phosphorus Doping of Floatzone Silicon, IEEE Trans. Electron Devices ED-23, 797-802 (1976).

32. Haas, E. W., and Schnöller, M. S., Phosphorus Doping of Silicon by Means of Neutron Irradiation, IEEE Trans. Electron Devices ED-23, 803-805 (1976).

33. Platzöder, K., and Loch, K., High-Voltage Thyristors and Diodes Made of Neutron-Irradiated Silicon, IEEE Trans. Electron Devices ED-23, 805-808 (1976).

34. Hill, M. J., van Iseghem, P. M., and Zimmerman, W., Preparation and Application of Neutron Transmutation Doped Silicon for Power Device Research, IEEE Trans, Electron Devices ED-23, 809-813 (1976).

35. Kolbesen, B. O., and Mayer, K. R., Striations als Ursache von Knickstellen in pn-übergängen von Leistungsbauelementen, Solid-State Electronics $17,1087-1090$ (1974).

36. Burtscher, J., Dorendorf, H. W., and Krausse, J., Electrical Measurement of Resistivity Fluctuations Associated With Striations in Silicon Crystals, IEEE Trans. Electron Devices ED-20, 702-708 (1973).

37. Choo, S. C. Effect of Carrier Lifetime on the Forward Characteristics of High Power Devices, IEEE Trans. Electron Devices ED-17, 647-652 (1970). 
38. Baliga, B. J. and Krishna, S., Optimization of Recombination levels and Their Capture Cross Section in Power Rectifiers and Thyristors, Solid-State Electronics 20, 225-232 (1977).

39. Malmros, O., Minority Carrier Lifetime of Neutron Doped Silicon, Neutron Transmutation Doping Conference, Columbia, MO, April 23-26, 1978, paper A-5.

40. Glairon, P. J. and Meese, M. M., Isochronal Annealing of Resistivity in Float Zone and Czochralski NTD-Silicon, Neutron Transmutation Doping Conference, Columbia, MO, April 23-26, 1978, paper B-3.

41. Baliga, B. J., and Evwaraye, A. O., Defect Levels Controlling the Behavior of Neutron Transmutation Doped Silicon During Annealing, Neutron Transmutation Doping Conference, Columbia, MO, April 23-26, 1978, paper B-5.

42. Cleland, J. W., Fleming, P. H., Larson, B. C., Narayan, J., Westbrook, R. D., Wood, R. F., and Young, R. T., Studies of Neutron-Transmutation-Doped Silicon at the Oak Ridge National Laboratory, Neutron Transmutation Doping Conference, Columbia, MO, April 23-26, 1978, paper C-1.

43. Graff, K., Hilgarth, J., and Neubrand, H., Process-Induced Defects in Oxygen and Carbon-Rich Silicon Crystals, Semiconductor Silicon/1977, H. R. Huff and E. Sirtl, Eds., pp. 575-584 (Electrochemical Society, Inc., Princeton, N.J., May 1977).

44. Ibid., Hill, M. J., and van Iseghem, P. M., Influence of Carbon Concentration on Gold Diffusion in Silicon, pp. 715-725.

45. Ibid., Bullis, W. M., and Vieweg-Gutberlet, F. G., Current Trends in Silicon Characterization Techniques, pp. 360-366.

46. Fairfield, J. M., and Gokhale, B. V., Control of Diffused Diode Recovery Time Through Gold Doping, Solid-State Electronics 9 , 905-907 (1966).

47. Lisiak, K. P., and Milnes, A. G., Platinum as a Lifetime-Control Deep Impurity in Silicon, J. Appl. Phys. 46, 5229-5235 (1975).

48. Baliga, B. J., and Sun, E., Comparison of Gold, Platinum, and Electron Irradiation for Controlling Lifetime in Power Rectifiers, IEEE Trans. Electron Devices ED-24, 685-688 (1977).

49. Carlson, R. O., Sun, Y. S., and Assalit, H. B., Control of Lifetime in Silicon Power Devices Using Electron or Gamma Radiation, PESC 77 Record, IEEE Power Electronics Specialists Conference, Palo Alto, CA, June 14-16, 1977, pp. 5-10. 
50. Comstock, W. R., and Locher, R. E., High Current Diode and SCR Reliability Considerations, PESC ' 75 Record, IEEE Power Electronics Specialists Conference, Culver City, CA, June 9-11, 1975, pp. 224-233.

51. Newell, W. E., Transient Thermal Analysis of Solid-State Power Devices - Making a Dreaded Process Easy, PESC 75 Record, IEEE Power Electronics Specialists Conference, Culver City, CA, June 9-il, 1975, pp. 234-251.

52. Jaecklin, A. A., and Lietz, M., Analysis of a Power Semiconductor Near its Threshold of Destruction, PESC ' 74 Record, IEEE Power Electronics Specialists Conference, Murray Hill, NJ, June 10-12, 1974, pp. 134-139.

53. Adler, M. S., and Glascock, H. H., Investigation of the Surge Characteristics of Power Rectifiers and Thyristors in Larqe Area Press Packages, PESC 78 Record, IEEE Power Electronics Specialists Conference, Syracuse, NY, June 13-15, 1978, to appear. 
Table 1

Manufacturers of Thyristors Rated $\geq 200 \mathrm{~A}, 2000 \mathrm{~V}$

U. S. Firms

*General Electric Co.

*International Rectifier Corp.

National Electronics, Inc. (division of Varian)

Power Semiconductors, Inc.

*Westinghouse Corp.

European Firms

AEG-Telefunken

*Almanna Svenska Elektriska AB (ASEA)

Associated Electrical Industries, Ltd.

*Brown, Boveri et Cie AG

CGEE Alsthom

Semikron

*Siemens AG

Westinghouse Brake and Signal Co. Ltd.

Japanese Firms

*Hitachi, Ltd.

*Mitsubishi Electric Corp.

*Nippon Electric Co., Ltd.

*Tokyo Shibaura Electric Co., Ltd. (Toshiba)

* Companies visited by Electron Devices Division staff members during 1976 and 1977. 
Table 2

Thermal Expansion and Conductivity Data*

Material

Exparision

$\mathrm{ppm} /{ }^{\circ} \mathrm{C}$

19.6

17.3

24.1

5.3

4.6

2.8

5.1

13.2

22.6

16.6

6.2

11.7

16.4

0.56
Conductivity

$\mathrm{W} / \mathrm{cm} \cdot \mathrm{K}$

4.18

4.0

2.38

2.3

1.7

1.5

1.4

0.9

0.65

0.65

0.40

0.40

0.14

0.014

*From American Institute of Physics Handbook, second ed., McGraw-Hill, 1963. 


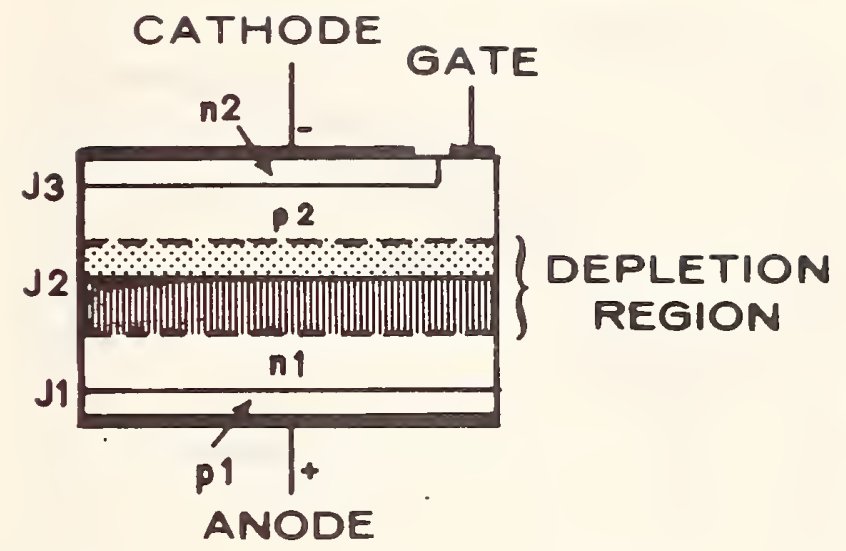

Figure 1. Cross-section of a thyristor in the forward-blocking off-state, showing the junction configuration and the depletion layer around junction $\mathrm{J} 2$.

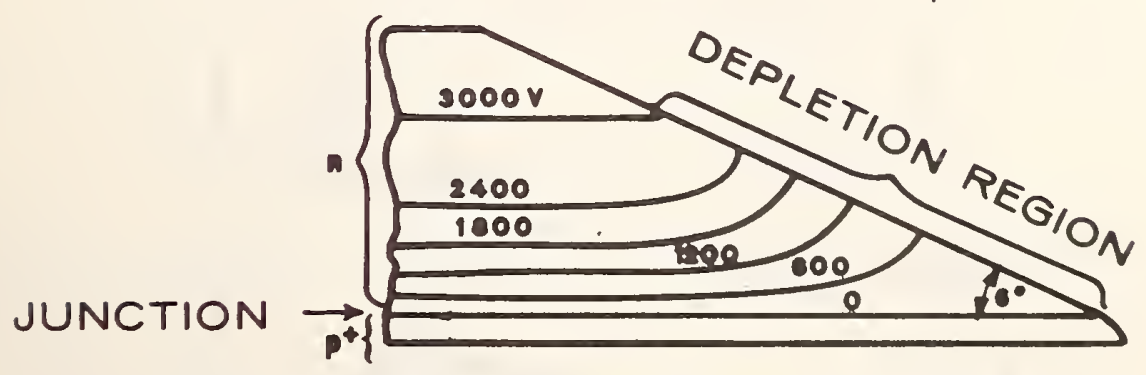

Figure 2. Equipotential lines in a reversebiased $p^{+}-n$ junction with a contoured surface (the relative scale is four vertical to one horizontal). 


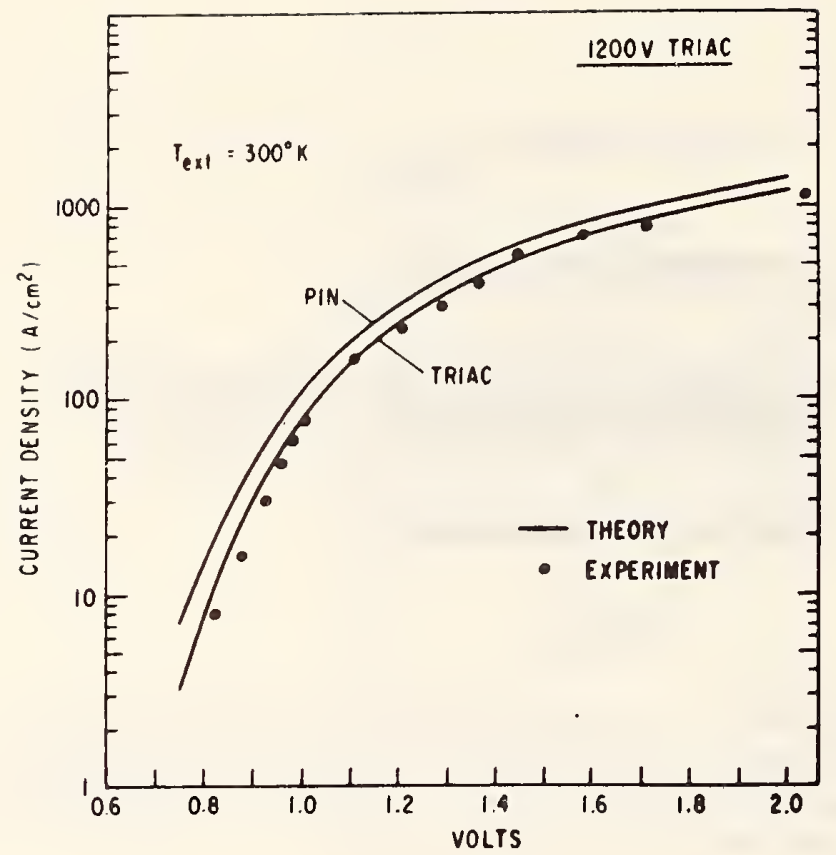

Figure 3a. Experimental and theoretical I-V curves for a $1200-\mathrm{V}$ triac.

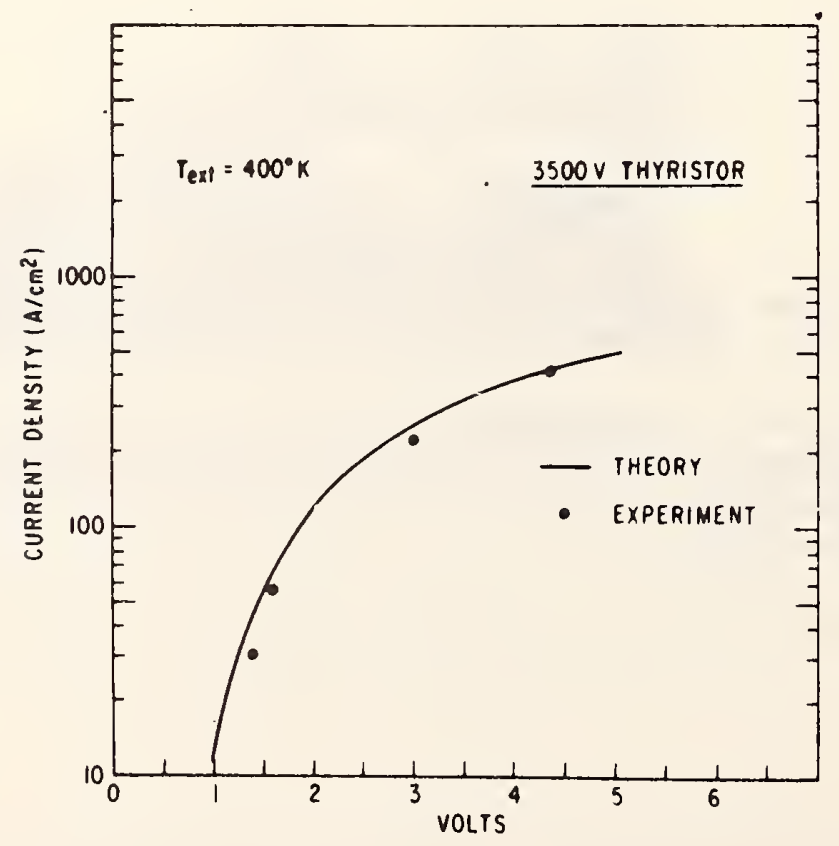

Figure 3b. Experimental and theoretical I-V curves for a $3500-\mathrm{V}$ thyristor. 


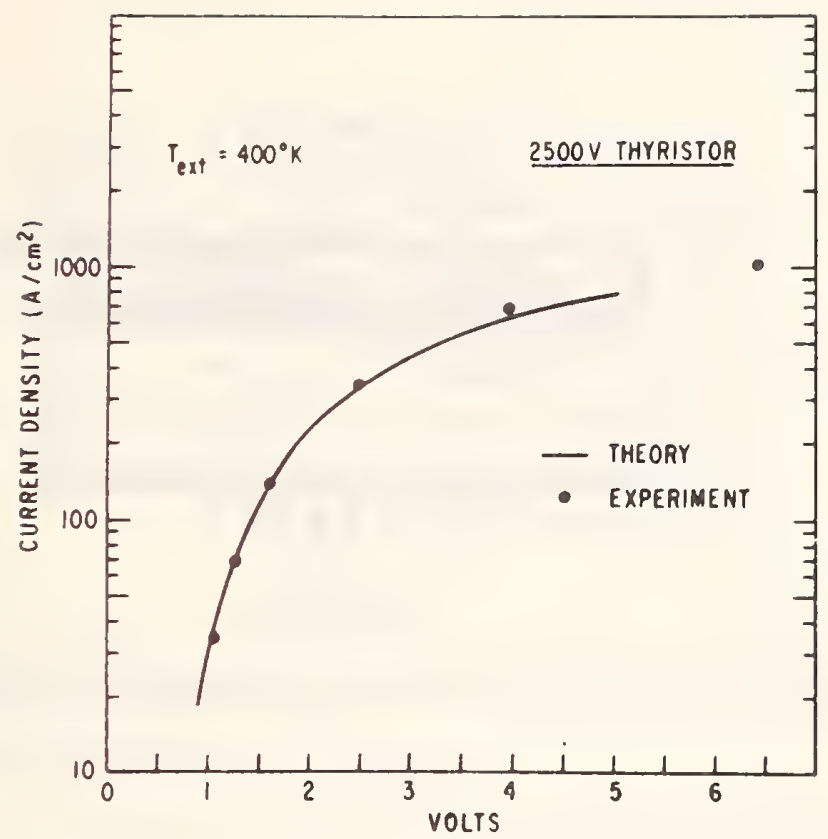

Figure 3c. Experimental and theoretical I-V curves for a $2500-\mathrm{V}$ thyristor.

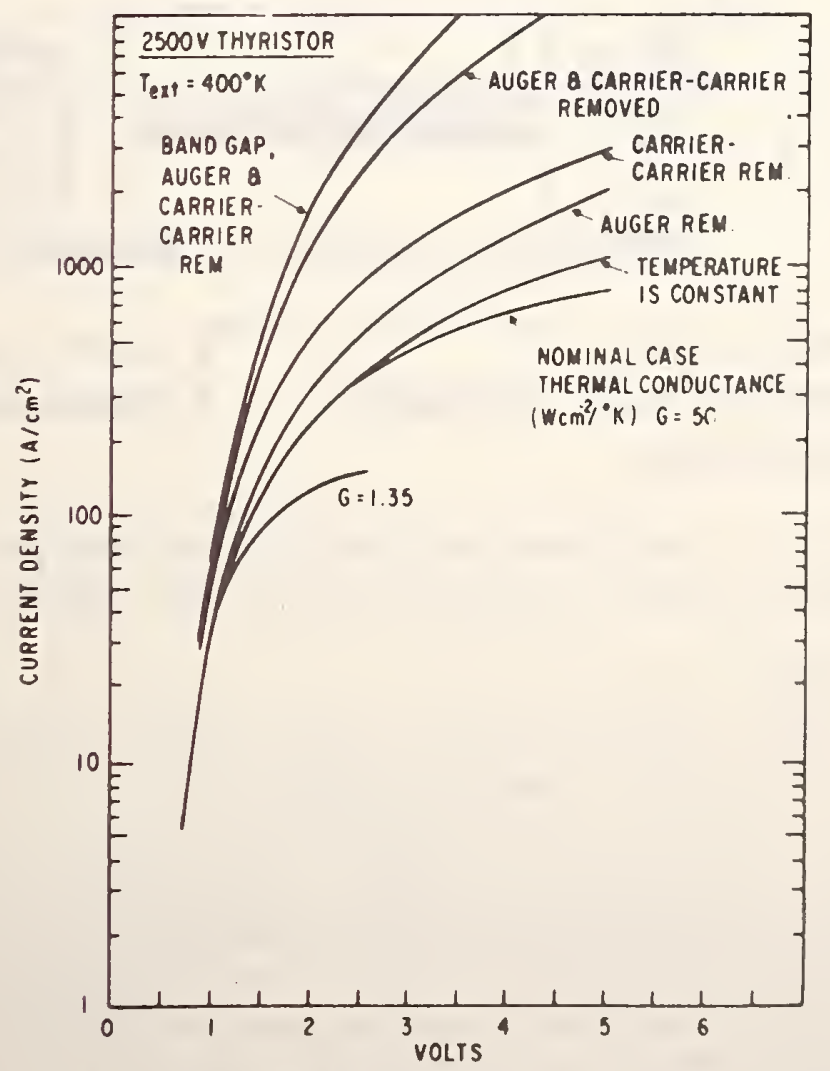

Figure 4. Theoretical curve which illustrates the relative importance of the various physical mechanisms, including heat flow, on the $I-V$ characteristics. 


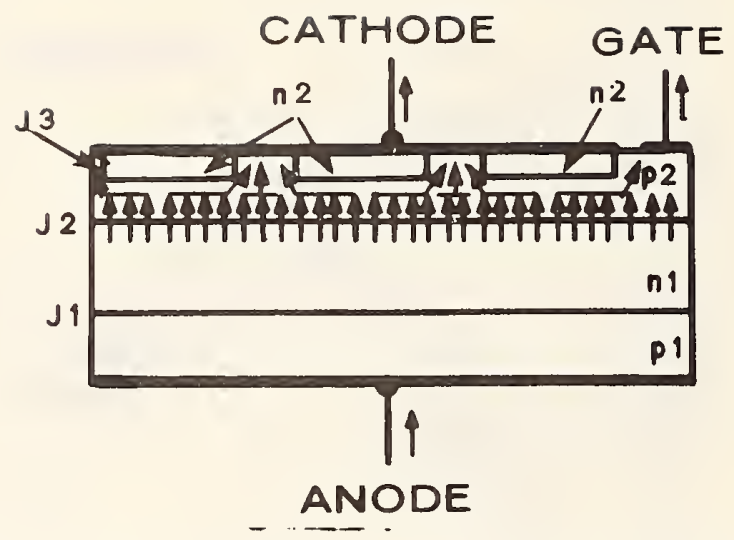

Figure 5. $p-n-p-n$ device with shorted emitter.

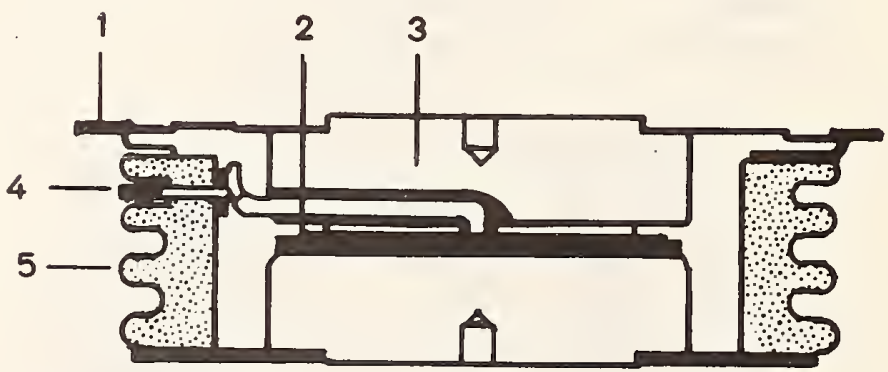

1 WELDED JOINT

2 THYRISTOR SUBASSEMBLY 3 CONDUCTORS
4 GATE CONNECTION

5 CERAMIC BODY

Figure 6. A thyristor for double-sided cooling. The conductors form an integral part of the capsule. 


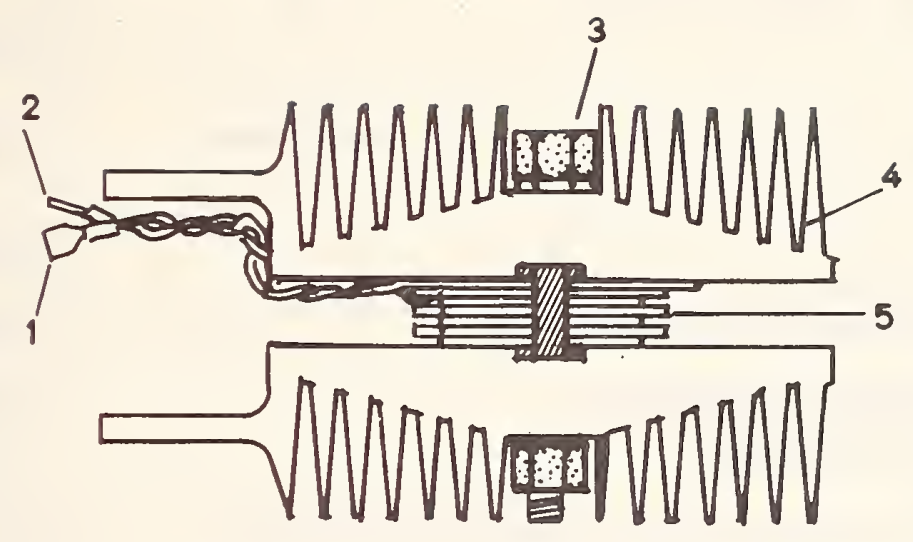

\section{AUXILIARY CATHODE 4 HEAT SINKS \\ 2 GATE CONNECTION 5 THYRISTOR DEVICE 3 COMPRESSION CLAMP}

Figure 7. Thyristor with double-sided air-cooled heat sinks.

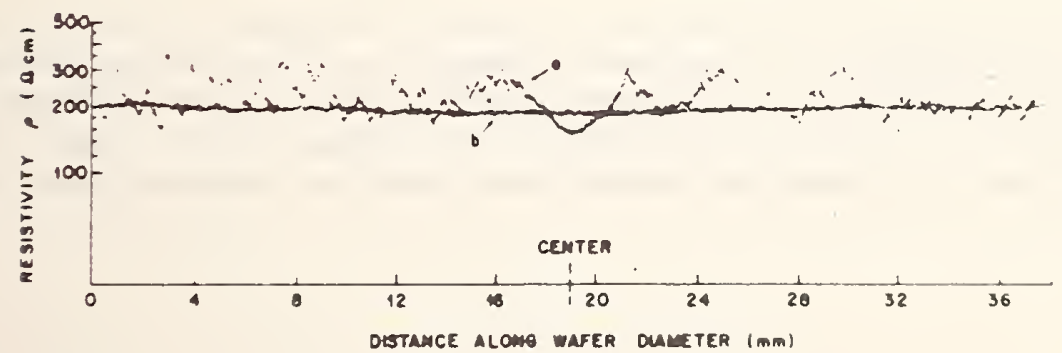

(a)

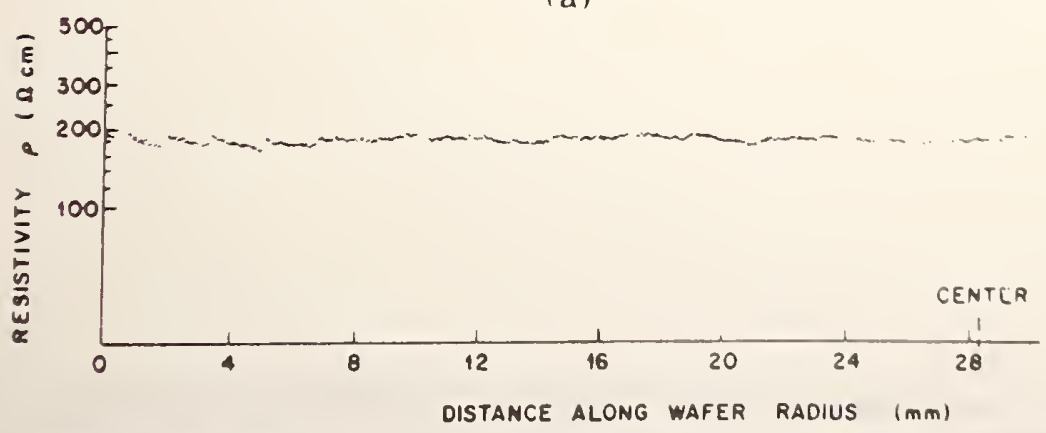

(b)

Figure 8. Spreading resistance measurements in silicon slices; distance between measurement points $20 \mathrm{im}$. (a) Diameters across $11 / 2-$ in slices of $200-\Omega \cdot \mathrm{cm} n-$ type FZ (curve a) and neutron transmutation doped silicon (curve b). (b) Radius of a 57-mm slice after neutron irradiation and annealing, showing small residual striations and variations, due to too small differences between initial and final resistivities. 
NBS-114A (REV. 5-78)

\begin{tabular}{|c|c|c|}
\hline $\begin{array}{l}\text { 1. PUBLICATION OR REPORT NO. } \\
\text { NBSIR 78-1559 }\end{array}$ & $\begin{array}{l}\text { 2. Gov't Accession } \\
\text { No. }\end{array}$ & 3. Recipient's Accession No. \\
\hline \multicolumn{2}{|l|}{ 4. TITLE AND SUBTITLE } & 5. Publication Date \\
\hline \multicolumn{2}{|c|}{ An Assessment of High Power Thyristor Technology } & 6. Performing Organization Code \\
\hline 7. AUTHOR(S) Robert I. Scace & & 8. Performing Organ. Report No. \\
\hline $\begin{array}{l}\text { 9. PERFORMING ORGANIZATION NAME AND ADDRESS } \\
\text { NATIONAL BUREAU OF STANDARDS } \\
\text { DEPARTMENT OF COMMERCE } \\
\text { WASHIMGTON, D.C. } 20234\end{array}$ & & $\begin{array}{l}\text { 10. Project/Task/Work Unit No. } \\
7216442 \\
\text { 11. Contract/Grant No. } \\
\text { EA-77-A-01-6010 } \\
\therefore \text { A021-EES amend.2 }\end{array}$ \\
\hline $\begin{array}{l}\text { 12. Sponsoring Otganization Name and Complete Address (Street, City, } \\
\text { Department of Energy }\end{array}$ & (e, ZIP) & $\begin{array}{l}\text { 13. Type of Report \& Period } \\
\text { Covered } \\
\text { Summary - no dates }\end{array}$ \\
\hline $\begin{array}{l}\text { Division of Electric Energy Systems } \\
\text { Washington, DC } 20545\end{array}$ & & 14. Sponsoring Agency Code \\
\hline
\end{tabular}

15. SUPP LEMENTARY NOTES

This work was conducted as a part of the Semiconductor Technology Program in the Electron Devices Division of NBS

16. ABSTRACT (A 200 word or less tactual summary of most significant in formation. If document includes a significant bibliography or literature survey, mention it here.)

The current state of the technology for designing and making high-power thyristors is reviewed. The discussion is confined primarily to thyristors having voltage ratings of $2000 \mathrm{~V}$ or greater, and current ratings above a few hundred amperes. Particular attention is given to describing the factors which limit the performance of such devices and to discussing recent work aimed at solving these problems.

17. KEY WORDS (six to twelve entries; alphabetical order; capitelize only the first lotler of the first key word unless a proper name; separated by semicolons)

High current switches; high voltage switches; SCR; semiconductor devices; semiconductor measurements; silicon devices; silicon controlled rectifiers; solid-state switches; technology assessment; thyristors.

\begin{tabular}{|c|c|c|}
\hline $\begin{array}{l}\text { 18. AVAILABILITY } \bar{X} \text { Unlimited } \\
\square \text { For Official Distribution. Do Not Release to NTIS }\end{array}$ & $\begin{array}{l}\text { 19. SECURITY CLASS } \\
\text { (THIS REPURT) } \\
\text { UNCL ASSIFIED }\end{array}$ & $\begin{array}{c}\text { 21. NO. OF PAGES } \\
42\end{array}$ \\
\hline $\begin{array}{l}\square \text { Order From Sup. of Doc., U.S. Government Printing Office } \\
\text { Washington, D.C. } 20402, \text { SD Stock No. SN003-003 }\end{array}$ & $\begin{array}{l}\text { 20. SECURITY CLASS } \\
\text { (THIS PAGE) }\end{array}$ & 22. Price \\
\hline $\begin{array}{l}X] \text { Order From National Technical Information Service (NTIS) } \\
\text { Springfield, Virginia } 22161\end{array}$ & UNCLASSIFIED & $\$ 4.50$ \\
\hline
\end{tabular}



